\title{
An association between polymorphism of the heme oxygenase-1 and -2 genes and age-related macular degeneration
}

\author{
Ewelina Synowiec $\cdot$ Jerzy Szaflik $\cdot$ Marta Chmielewska $\cdot$ Katarzyna Wozniak \\ Anna Sklodowska • Maja Waszczyk • Mariola Dorecka • Janusz Blasiak • \\ Jacek Pawel Szaflik
}

Received: 29 December 2010/ Accepted: 26 May 2011/Published online: 7 June 2011

(C) The Author(s) 2011. This article is published with open access at Springerlink.com

\begin{abstract}
Iron may be implicated in the generation of oxidative stress by the catalyzing the Haber-Weiss or Fenton reaction. On the other hand, oxidative stress has been implicated in the pathogenesis of age-related macular degeneration (AMD) and heme oxygenase-1 (HO-1), encoded by the HMOXI gene and heme oxygenase-2 (HO2), encoded by the HMOX2 gene are important markers of iron-related oxidative stress and its consequences. Therefore, variability of the HMOX1 and HMOX2 genes might be implicated in the pathogenesis of AMD through the modulation of the cellular reaction to oxidative stress. In the present work, we investigated the association between $\mathrm{AMD}$ and $\mathrm{a} \mathrm{G} \rightarrow \mathrm{C}$ transversion at the 19 position in the HMOX1 gene (the 19G $>$ C-HMOX1 polymorphism, rs2071747) and a $\mathrm{A} \rightarrow \mathrm{G}$ transition at the $-42+1444$ position in the HMOX2 gene (the $-42+1444 \mathrm{~A}>\mathrm{G}-$ HMOX2 polymorphism, rs2270363) and its modulation by some environmental factors. 279 patients with AMD and 105 controls were recruited in this study and the polymorphisms were typed by restriction fragment length
\end{abstract}

Electronic supplementary material The online version of this article (doi:10.1007/s11033-011-0955-3) contains supplementary material, which is available to authorized users.

E. Synowiec $\cdot$ M. Chmielewska $\cdot$ K. Wozniak $\cdot$ J. Blasiak Department of Molecular Genetics, University of Lodz, Pomorska 141/143, 90-236 Lodz, Poland

J. Szaflik · A. Sklodowska - M. Waszczyk · J. P. Szaflik ( $\square)$ Department of Ophthalmology, Medical University of Warsaw and Samodzielny Publiczny Kliniczny Szpital Okulistyczny, ul. Sierakowskiego 13, 03-710 Warsaw, Poland

e-mail: szaflik@ophthalmology.pl

M. Dorecka

Department of Ophthalmology, Medical University of Silesia, ul. Ceglana 35, 40-514 Katowice, Poland polymorphism and allele-specific polymerase chain reaction (PCR). We observed an association between the occurrence of dry AMD and the G/A genotype of the $-42+1444 \mathrm{~A}>\mathrm{G}-$ HMOX 2 polymorphism (odds ratio (OR) 2.72), whereas the $\mathrm{G} / \mathrm{G}$ genotype reduced the risk of dry AMD (OR 0.41). The G/C genotype and the $\mathrm{C}$ allele of the $19 \mathrm{G}>\mathrm{C}-\mathrm{HMOX} 1$ polymorphism and the $\mathrm{G} / \mathrm{G}$ genotype and the $\mathrm{G}$ allele of the $-42+1444 \mathrm{~A}>\mathrm{G}-$ HMOX 2 polymorphism were associated with progression of AMD from dry to wet form (OR 4.83, 5.20, 2.55, 1.69, respectively). On the other hand, the G/G genotype and the $G$ allele of the $19 \mathrm{G}>\mathrm{C}-\mathrm{HMOX} 1$ polymorphism and the $\mathrm{A} / \mathrm{G}$ genotype and the $\mathrm{A}$ allele of the $-42+1444 \mathrm{~A}>\mathrm{G}-\mathrm{HMOX} 2$ polymorphism protected against AMD progression (OR 0.19, 0.19, $0.34,0.59$, respectively). Therefore, the $19 \mathrm{G}>\mathrm{C}-\mathrm{HMOXI}$ and the $-42+1444 \mathrm{~A}>\mathrm{G}-\mathrm{HMOX} 2$ polymorphisms may be associated with the occurrence and progression of AMD.

Keywords Age-related macular degeneration - AMD . Heme oxygenase-1 and -2 HMOX1, HMOX2 - Gene . Polymorphism

\section{Introduction}

Age-related macular degeneration (AMD) is an eye disease that results in a progressive and irreversible loss of central vision and is considered as the primary cause of visual impairment, including blindness in the elderly, in industrialized countries $[1,2]$. This disease affects the retinal pigment epithelium (RPE), Bruch's membrane (BM) and choriocapillaries [3,4]. The etiology of AMD is not fully understood and it is likely underlined by a complex interaction between genetic and environmental factors [5]. The latter are age, smoking, sex, Caucasian ethnicity, chronic 
sunlight exposure, overweight and obesity and cardiovascular diseases [6-9]. A number of epidemiological studies has indicated AMD as an inherited disease, showing that family members are at an increased risk [10-15].

Several studies on the molecular character of AMD suggest an important role of oxidative stress in its pathology. The retina in general, and macula in particular are highly susceptible to oxidative stress because of elevated oxygen pressure, high metabolic activity, prolonged exposure to UV and blue light, presence of photosensitizers and oxidative phagocytosis of photoreceptors. Also iron overload in the retina may contribute to its oxidative damage by the catalyzing Haber-Weiss and Fenton reactions, producing reactive oxygen species (ROS) $[16,17]$. AMD may be exacerbated by retinal iron overload and eyes with macular degeneration showed elevated levels of iron in the RPE, BM and within drusen [18]. Moreover, the concentration of retinal iron increases with age [19].

Several enzymes are important in the formation and reduction of iron-generated ROS. Heme oxygenase-1 (HO1), encoded by the HMOXI gene and the closely related heme oxygenase-2 (HO-2), encoded by the HMOX2 gene, convert heme, a powerful pro-oxidant, to biliverdin, which is then changed to bilirubin, a strong antioxidant, by the enzyme biliverdin reductase. Because of this activity, HOs may have an important role in oxidative stress-related diseases, including AMD. HO-1 and HO-2 levels were found to decrease with age in RPE cells from eyes with evidence of neovascular AMD [20].

As HO-1 and HO-2 may be involved in AMD, the variation in the sequence of their genes may also contribute to this disease. Many studies confirmed the association between genetic variability and AMD [21-26]. In the present work we investigated the association between a $\mathrm{G} \rightarrow \mathrm{C}$ transversion at the 19 position in the HMOX1 gene (the 19G $>$ C-HMOXI polymorphism, rs2071747) and an $\mathrm{A} \rightarrow \mathrm{G}$ transition at the $-42+1444$ position in the HMOX 2 gene (the $-42+1444 \mathrm{~A}>\mathrm{G}-H M O X 2$ polymorphism, rs2270363) and AMD. We also investigated the modulation of such possible association by some clinical and life-style factors. The $19 \mathrm{G}>\mathrm{C}-$ HMOX1 polymorphism is located in the coding region (exon 1) of the HMOX1 gene, while the other polymorphism is in the $5^{\prime}$ flanking region of the HMOX2 gene. We chose polymorphisms with a minor allele frequency $\geq 3 \%$ in an European population. The 19G $>$ C-HMOX1 polymorphism is a non-synonymous mutation resulting in an Asp to His substitution in the 7 codon. Non-synonymous coding polymorphisms along with the polymorphism in the regulatory region of a gene are believed to comprise a group of single nucleotide polymorphisms (SNPs) that may the highest potential phenotypic influence [27].

\section{Materials and methods}

Study subjects and data collection

Blood samples were obtained from 279 patients with AMD and from 105 individuals without visual disturbances. Among AMD patients, 101 had dry AMD and the remaining 178-wet form of this disease. The characteristics of patients and controls enrolled in this study are presented in Supplementary Table 1. All patients and controls were examined in the Department of Ophthalmology, Medical University of Warsaw (Warsaw, Poland). They underwent ophthalmic examination, including bestcorrected visual acuity, intraocular pressure, slit lamp examination, and fundus examination, performed with a slit lamp equipped with either non-contact or contact fundus lenses. Diagnosis of AMD was confirmed by optical coherence tomography (OCT) and, in some cases, by fluorescein angiography (FA) and indocyanin green angiography (ICG). OCT evaluated retinal thickness, the presence of RPE atrophy, drusen, or subretinal fluid and intraretinal edema; angiography assessed the anatomical status of the retinal vessels, the presence of choroidal neovascularization and leakage. The OCT examinations were performed with Stratus OCT model 3000, software version 4.0 (Oberkochen, Germany). The FA and ICG examinations were performed with a Topcon TRC-50I IX fundus camera equipped with the digital Image Net image system, version 2.14 (Topcon, Tokyo, Japan). The study design was approved by the Bioethics Committee of the Medical University of Warsaw and each subject gave a written informed consent. Each subject was interviewed to provide data on tobacco smoking (never/ever), alcohol use (never/ever) and other risk factors: sex, negative and positive family history for AMD, age, living environment (rural or urban areas). Each subject donated a $5 \mathrm{ml}$ volume venous blood sample, $250 \mu \mathrm{l}$ of which was used for the extraction of genomic DNA. All samples were coded after collection of blood and completing the questionnaire.

\section{Selection of SNPs for HMOX1 and HMOX2} and primer design

A list of SNPs in the HMOX1 and HMOX2 genes was obtained from the public domain of the National Center for Biotechnology Information at http://www.ncbi.nlm.nih. gov/snp. We chose SNPs with a minor allele frequency not lesser than $3 \%$ in the European population. Primers were designed using the HMOXI and HMOX2 genomic sequence found at http://www.ensembl.org/Homo_sapiens/ Gene/Sequence?g=ENSG00000100292;r=22:35776354-35 790207 and http://www.ensembl.org/Homo_sapiens/Gene/ Sequence?g=ENSG00000103415;r=16:4524719-4560348) 
and Primer3Plus software (http://www.bioinformatics. nl/cgi-bin/primer3plus/primer3plus.cgi).

DNA extraction and storage

Genomic DNA was prepared by using the commercial AxyPrep $^{\mathrm{TM}}$ Blood Genomic DNA Miniprep Kit (Axygen Biosciences, Union City, CA, USA), according to the manufacturer's instructions. DNA purity and concentrations were determined spectrophotometrically at 260 and $280 \mathrm{~nm}$. The purified genomic DNA was stored in TE buffer (5 mM Tris- $\mathrm{HCl}, 0.1 \mathrm{mM}$ EDTA, $\mathrm{pH} 8.5$ ), at $-20^{\circ} \mathrm{C}$ until use.

\section{Genotyping}

The genotypes of the $19 \mathrm{G}>\mathrm{C}-H M O X 1$ polymorphism were determined by the allele-specific oligonucleotidePCR method. PCR assay was performed in a total volume of $25 \mu \mathrm{l}$ containing $50 \mathrm{ng}$ of genomic DNA, $1 \mathrm{U}$ Biotools DNA polymerase (Biotools, Madrid, Spain), $1 \times$ reaction buffer (750 mM Tris-HCl, pH 9.0, $500 \mathrm{mM} \mathrm{KCl,} 200 \mathrm{mM}$ $\left.\left(\mathrm{NH}_{4}\right)_{2} \mathrm{SO}_{4}\right), 0.2 \mathrm{mM}$ of each dNTP, $1.5 \mathrm{mM} \mathrm{MgCl}_{2}$, $0.25 \mu \mathrm{M}$ of each primers (Metabion, Martinsried, Germany). Thermal cycling conditions were as follows: initial denaturation step at $95^{\circ} \mathrm{C}$ for $5 \mathrm{~min}, 35$ cycles at $95^{\circ} \mathrm{C}$ for $30 \mathrm{~s}, 60 \mathrm{~s}$ at $63^{\circ} \mathrm{C}$ annealing temperature and $60 \mathrm{~s}$ at $72^{\circ} \mathrm{C}$. The final extension step was performed for $7 \mathrm{~min}$ at $72^{\circ} \mathrm{C}$. The following primers were used: allele-specific sense oligonucleotides: 5'-GGATGGAGCGTCCGCAACCCC-3' for $\mathrm{C}$ variant and $5^{\prime}$-GGATGGAGCGTCCGCAACCCG-3' for $\mathrm{G}$ variant and antisense oligonucleotide: 5'-CGCATA CCAGGGTGCCAGGCAT-3'. The PCR products (241 bp) were run onto a $3 \%$ agarose gel, stained with ethidium bromide and viewed under UV light. Supplementary Fig. 1 presents a representative gel for analysis of this polymorphism.

The polymerase chain reaction-restriction fragment length polymorphism (PCR-RFLP) method was used to determine the genotypes of the $-42+1444 \mathrm{~A}>\mathrm{G}-$ HMOX2 polymorphism. PCR assay was performed in a total reaction volume of $25 \mu \mathrm{l}$ containing the same chemicals as in the previous analysis except for primers. 385-bp length fragments containing polymorphic site were amplified using the following primers: sense 5'-GGTGGTGCCAC GGTTGACAA- $3^{\prime}$ and antisense $5^{\prime}$-GTCCGCCAGCCTC CAGTCAG- $3^{\prime}$. The PCR profile contained an initial denaturation step for $5 \mathrm{~min}$ at $95^{\circ} \mathrm{C}, 30$ cycles at $95^{\circ} \mathrm{C}$ for $30 \mathrm{~s}, 30 \mathrm{~s}$ at $65^{\circ} \mathrm{C}$ annealing temperature and $60 \mathrm{~s}$ at $72^{\circ} \mathrm{C}$ and the final extension step for $5 \mathrm{~min}$ at $72^{\circ} \mathrm{C}$. After amplification, the $385-\mathrm{bp}$ PCR products were analyzed in a $3 \%$ agarose gel and digested with $1 \mu \mathrm{l}$ of FastDigest NlaIII
(Hin1II) restriction endonuclease (Fermentas, Hanover, $\mathrm{MD}, \mathrm{USA}$ ) in a final volume of $15 \mu \mathrm{l}$ for $5 \mathrm{~min}$ at $37^{\circ} \mathrm{C}$. PCR products with a $\mathrm{G}$ at the polymorphic site were digested into two fragments of 211 and $174 \mathrm{bp}$, while those with an $\mathrm{A}$ at this site were not cleaved because of the absence of a NlaIII restriction site. The $\mathrm{G} / \mathrm{G}$ genotype produced two fragments (211 and $174 \mathrm{bp}$ ), whereas the G/A genotype produced three fragments $(385,211,174 \mathrm{bp})$ and the homozygote $\mathrm{A} / \mathrm{A}$ resulted in one fragment of 385 bp. Digested PCR products were separated by electrophoresis on a $8 \%$ polyacrylamide gel and visualized by ethidium bromide staining using a GeneRuler ${ }^{\mathrm{TM}} 100 \mathrm{bp}$ (Fermentas, Hanover, MD, USA) as a size marker. A representative gel for this polymorphism is presented in Supplementary Fig. 2.

All PCR amplifications were conducted in a C1000 Thermal Cycler (Bio-Rad Laboratories, Hercules, CA, USA). All experiments included positive and negative controls for each polymorphism. We randomly selected $10 \%$ of 383 samples for repeated assays and the results were $100 \%$ concordant.

\section{Statistical analysis}

All statistical analyses were performed using STATISTICA 9.0 software (Statsoft, Tulsa, OK, USA) and SigmaPlot v11.0 software (Systat Software, Inc., San Jose, CA, USA). To compare the distributions of demographic variables and selected risk factors between patients and controls $\chi^{2}$ test was used. Hardy-Weinberg equilibrium was checked using $\chi^{2}$ test to compare the observed genotype frequencies with the expected frequencies among the case and control subjects. The $\chi^{2}$ analysis was also used to test the significance of the differences between distributions of genotypes and alleles in AMD patients and controls. The association between case-control status and each polymorphism, measured by the odds ratio (OR) and its corresponding 95\% confidence interval (CI), was estimated using an unconditional multiple logistic regression model, both with and without adjustment for sex, age, smoking habit, living environment (rural vs. urban areas) and family status of AMD. Tobacco smoking habit was categorized in terms of never smokers and smokers, including current and former smokers. Stratified analysis according to age, sex and family status of AMD was also conducted. To study a possible gene-environment interaction, the patients and controls were divided into subgroups depending on sex, family history and age. Unconditional logistic regression analyses were also performed to assess the association between genotypes and risk for AMD after stratification of the individuals according to sex, age and family status of AMD. 


\section{Results}

The PCR-RFLP and ASO-PCR analyses were successful for all controls, but we were not able to determine the genotypes of both polymorphisms for seven AMD patients.

Characteristics of the study population

The characteristic of the patients and controls is presented in Supplementary Table 1. For six AMD patients we had not information about sex and age. There were significantly more subjects with negative family history for AMD among the controls than patients $(96 \%$ vs. $80 \%$, $P<0.001)$. Therefore, these variables were further adjusted for in the multivariate logistic regression model to control for possible confounding of the main effects of the polymorphisms.

Relationship between age, sex, tobacco smoking, living environment and AMD in family and the risk of AMD independent of genotype

We investigated relationship between age, sex, smoking, living environment and family history of AMD and the risk of AMD independently of genotype. We compared controls and AMD patients according to these parameters (Supplementary Table 2). Male sex (OR 1.78, 95\% CI 1.05-3.02; $P=0.031)$, age (7.77, 95\% CI 2.73-22.12; $P<0.001)$ and family history of AMD (OR 6.80, 95\% CI $2.02-22.90 ; P=0.002)$ significantly increased the risk of AMD.

Polymorphisms of the HMOX-1 and -2 genes and the risk of AMD

The genotype and allele distributions of the $19 \mathrm{G}>\mathrm{C}$ HMOX 1 and $-42+1444 \mathrm{~A}>\mathrm{G}-$ HMOX 2 polymorphisms in AMD patients and controls are summarized in Supplementary Table 3 . The genotype frequencies were all in agreement with the Hardy-Weinberg equilibrium calculated for the cases and controls $(P>0.05$, data not show). As shown in Supplementary Table 3 the difference in the frequency distributions of genotypes between the cases of dry AMD and controls was statistically significant $(P<0.05)$. A weak association between dry AMD occurrence and the G/A genotype of the $-42+1444 \mathrm{~A}>$ G-HMOX2 polymorphism was found, whereas the homozygous variant $\mathrm{G} / \mathrm{G}$ was associated with a significant reduction in dry AMD risk. Moreover, the A allele of this polymorphism was positively correlated with the occurrence of dry AMD, whereas the $\mathrm{G}$ allele had a protective effect against dry AMD. We did not observe any association between the occurrence of AMD its dry or wet form and genotypes/alleles of the other polymorphism.

Additionally, we studied the distribution of genotypes and alleles of the polymorphisms in the group of wet AMD patients in comparison with dry AMD patients (Supplementary Table 4). Such comparison was considered as a measure of AMD progression. The $\mathrm{G} / \mathrm{C}$ genotype and the $\mathrm{C}$ of the $19 \mathrm{G}>\mathrm{C}-H M O X 1$ polymorphism and the G/G genotype and the $\mathrm{G}$ allele of the $-42+1444 \mathrm{~A}>\mathrm{G}-H M O X 2$ polymorphism increased progression of AMD. Furthermore, the G/G genotype and the $\mathrm{G}$ allele of the $19 \mathrm{G}>\mathrm{C}$ HMOX1 polymorphism and the G/A genotype and the $\mathrm{A}$ allele of the HMOX2 SNP may have a protective effect against disease progression.

Gene-gene interaction and AMD occurrence and progression

We also assessed the association between the occurrence and progression of AMD and combined genotypes of the 19G $>\mathrm{C}-$ HMOX1 and $-42+1444 \mathrm{~A}>\mathrm{G}-$ HMOX 2 polymorphisms. The distribution of combined genotypes of these polymorphisms are shown in Supplementary Tables 5 and 6. The presence of the combined G/G-G/A genotype increased the risk of dry AMD, while the presence of the $\mathrm{G} / \mathrm{G}-\mathrm{G} / \mathrm{G}$ genotype decreased such risk.

Gene-gene interaction resulted in a slight increase in the AMD progression from dry to wet form with the combined G/G-G/G genotype, whereas the G/G genotype of the 19G $>$ C-HMOX1 polymorphism and the $\mathrm{A} / \mathrm{G}$ genotype of the $42+1444 \mathrm{~A}>\mathrm{G}-H M O X 2$ polymorphism were associated with a protective effect against progression of the disease.

Gene-environment interaction and AMD occurrence and progression

The association between AMD and the 19G $>$ C-HMOXI and the $-42+1444 \mathrm{~A}>\mathrm{G}-$ HMOX 2 polymorphism was subjected to stratification analysis, but only data for the $-42+1444 \mathrm{~A}>\mathrm{G}-$ HMOX2 are presented in Supplementary Table 7 because such analysis for other polymorphism did not yield any significant result. In stratification analysis, the G/G genotype was associated with a significantly decreased risk of AMD in subgroups of subjects of 61 years and older, women and subjects with no AMD history in family. Moreover, the G/A genotype was associated with a significantly increased risk of AMD in subgroups of patients older than 61 years, women and subjects with a negative family history for AMD. 


\section{Discussion}

AMD is the leading cause of irreversible blindness in the elderly in developed countries. As the elderly population grows, age-related diseases, including AMD, become more prevalent [28]. Approximately 25-30 million people globally are affected by AMD and this number is expected to triple over the next 25 years. The development of AMD is a gradual process. Its progression occurs over an extended time frame, with the incidence of the disease increasing dramatically above 70 years old. Aging is associated with changes in the retina, including alterations in RPE cellular size and shape, thickening of BM, thickening of the internal limiting membrane and a decrease in retinal neuronal elements [29]. Generally, two types of AMD can be considered: dry and wet [30], wherein dry AMD accounts for $80-90 \%$ and wet AMD for $10-20 \%$ of all cases. The majority of vision loss $(\sim 90 \%)$ is attributed to wet AMD, which is the last and most severe phase of macular degeneration progress [31]. The relationship between dry and wet forms of AMD is not definite and dry AMD may or may not eventually develop into the wet form. It is estimated that dry form progresses to the wet form in approximately $10 \%$ of cases. Therefore, our attitude comparing the percentage of wet and dry cases as a marker of the progression of AMD is limited.

Although the etiology and pathogenesis of AMD remain largely unclear, a several genetic factors in combination with environmental and lifestyle factors may be involved in them. Results of several studies have shown that the most recognized factors are advanced age, cigarette smoking, race and diet $[8,9]$. In the first stage of our study, we examined the relationship between clinical, environmental and life style parameters and risk of AMD independently of genotype. Our findings suggest that age, sex and family status of AMD are risk factors in the development of the disease. This is in general agreement with results obtained by others $[11,32]$. However, we did not find any association between tobacco smoking and AMD. At present we have not any direct explanation of this fact except that tobacco smoking may be one of the factor of AMD pathogenesis and not the sole reason of AMD and the role of this factor depends on the population. Therefore, more detailed characteristics of the population enrolled in the present study might clear this issue.

Mitochondria belong to the major sources of ROS in human lens epithelial cells. A growing body of evidence suggests that mitochondria have a central role in agerelated disorders, including retinal diseases. Mitochondriaassociated diseases are recognized as a variety of many important clinical entities that develop as a consequence of abnormalities in energy supply, generators of ROS and initiators of apoptotic processes [33].
During the aging, the balance between the generation and clearance of ROS can be disturbed resulting in an oxidative damage to outer segments of photoreceptors and progressive deterioration of the RPE [34]. Several enzymes are important in the formation and reduction of ROS. The HO-1 and HO-2 may have an important role in diseases that involve oxidative stress, including AMD. Frank et al. [20] observed reduction in both HO-1 and HO-2 protein in old age and in RPE cells from eyes with evidence of neovascular AMD. Likewise, Miyamura et al. [35] found an age-related decline in HO-1 mRNA expression in the macula and the periphery of human subjects. Interestingly, an overexpression of HO-1 in photoreceptors protected them from subsequent cellular damage caused by an intense light exposure [36].

In general, the role of genetic variability in AMD has been extensively studied. Numerous case-control studies have confirmed the association between SNPs and AMD [21-26]. Recent studies also report a significant association between the genetic polymorphism of genes encoding antioxidant enzymes and development of AMD [37, 38]. Polymorphisms in the HMOX1 and HMOX2 genes have not been studied in AMD patients so far. The human HMOX-1 gene is located at 22q12 and consists of five exons spanning $\sim 14 \mathrm{~kb}$ separated by four introns $[39,40]$. We analyzed a $\mathrm{G}$ to $\mathrm{C}$ transversion located at the +19 cDNA position in the first exon of the HMOX-1 gene. This polymorphism causes change of aspartic acid to histidine at the amino acid position 7 of the HO-1 protein, but the clinical role of this change is unknown. A non-synonymous SNP site with a low gene diversity, relative to other SNP sites in the same gene that do not cause amino acid changes, might constitute a good candidate allele for disease association [41]. Such substitution may directly affect the structure and stability of protein with a serious phenotypic consequences $[42,43]$. We found that the occurrence of the $\mathrm{G} / \mathrm{C}$ genotype and the $\mathrm{C}$ allele of the $\mathrm{c} .19 \mathrm{G}>\mathrm{C}$ polymorphism of the HMOXI gene increased the progression of AMD. Other studies showed that this SNP was not associated with Alzheimer's disease in Japanese population and Parkinson's disease in German population [44, 45]. The other polymorphism, $-42+1444 \mathrm{~A}>\mathrm{G}-\mathrm{HMOX} 2$, is located in the $5^{\prime}$ flanking region of the gene, consisting of five exons spanning $\sim 12 \mathrm{~kb}[39,40]$. HO-1 (32 kDa) and HO$2(36 \mathrm{kDa})$ share roughly $40 \%$ amino acid homology [46].

In summary, our results suggest that the $19 \mathrm{G}>\mathrm{C}$ polymorphism of the HMOXI gene and the $-42+1444 \mathrm{~A}>\mathrm{G}$ polymorphism of the HMOX2 gene may be associated with individual susceptibility to AMD. The identification of SNPs that are associated with variation in gene expression in the retina and in the eye in general might help to identify specific molecular signatures of AMD and ultimately help to improve quality of life of AMD patients. 


\section{Conclusion}

In conclusion, our findings suggest that the $19 \mathrm{G}>\mathrm{C}-H M O X 1$ polymorphism and the $-42+1444 \mathrm{~A}>\mathrm{G}-\mathrm{HMOX} 2$ polymorphism may be linked with the development of AMD.

Acknowledgments This study was supported by the grant number N N402 248336 of Ministry of Science and Higher Education.

Conflict of interest statement The authors declare that there are no conflicts of interest.

Open Access This article is distributed under the terms of the Creative Commons Attribution Noncommercial License which permits any noncommercial use, distribution, and reproduction in any medium, provided the original author(s) and source are credited.

\section{References}

1. World Health Organization (WHO) (2009) Priority eye diseases. http://www.who.int/blindness/causes/priority/en/index 8.html. Accessed 20 Oct 2009

2. Gehrs KM, Anderson DH, Johnson LV, Hageman GS (2006) Age-related macular degeneration-emerging pathogenetic and therapeutic concepts. Ann Med 38:450-471

3. Fine SL, Berger JW, Maguire MG, Ho AC (2000) Age-related macular degeneration. N Engl J Med 342:483-492

4. Stone EM, Sheffield VC, Hageman GS (2001) Molecular genetics of age-related macular degeneration. Hum Mol Genet 10:22852292

5. Chen Y, Bedell M, Zhang K (2010) Age-related macular degeneration: genetic and environmental factors of disease. Mol Interv 10:271-281

6. Clemons TE, Milton RC, Klein R, Seddon JM, Ferris FL III (2005) Age-Related Eye Disease Study Research Group. Risk factors for the incidence of Advanced Age-Related Macular Degeneration in the Age-Related Eye Disease Study (AREDS) AREDS report no. 19. Ophthalmology 112:533-539

7. van Newkirk MR, Nanjan MB, Wang JJ, Mitchell P, Taylor HR, McCarty CA (2000) The prevalence of age-related maculopathy: the visual impairment project. Ophthalmology 107:1593-1600

8. Coleman HR, Chan CC, Ferris FL III, Chew EY (2008) Agerelated macular degeneration. Lancet 372:1835-1845

9. Jager RD, Mieler WF, Miller JW (2008) Age-related macular degeneration. N Engl J Med 358:2606-2617

10. Meyers SM (1994) A twin study on age-related macular degeneration. Trans Am Ophthalmol Soc 92:775-843

11. Smith W, Mitchell P (1998) Family history and age-related maculopathy: the Blue Mountains Eye Study. Aust NZ J Ophthalmol 26:203-206

12. Hyman L, Neborsky R (2002) Risk factors for age-related macular degeneration: an update. Curr Opin Ophthalmol 13:171-175

13. Klein ML, Francis PJ (2003) Genetics of age-related macular degeneration. Ophthalmol Clin N Am 16:567-574

14. Seddon JM, Santangelo SL, Book K, Chong S, Cote J (2003) A genome wide scan for age-related macular degeneration provides evidence for linkage to several chromosomal regions. Am J Hum Genet 73:780-790

15. Scholl HP, Fleckenstein M, Charbel Issa P, Keilhauer C, Holz FG, Weber BH (2007) An update on the genetics of age-related macular degeneration. Mol Vis 13:196-205
16. Welch KD, Davis TZ, Van Eden ME, Aust SD (2002) Deleterious iron-mediated oxidation of biomolecules. Free Radic Biol Med 32:577-583

17. Reddy MB, Clark L (2004) Iron, oxidative stress, and disease risk. Nutr Rev 62:120-124

18. Wong RW, Richa DC, Hahn P, Green WR, Dunaief JL (2007) Iron toxicity as a potential factor in AMD. Retina 27:997-1003

19. Hahn P, Ying GS, Beard J, Dunaief JL (2006) Iron levels in human retina: sex difference and increase with age. Neuroreport 17:1803-1806

20. Frank RN, Amin RH, Puklin JE (1999) Antioxidant enzymes in the macular retinal pigment epithelium of eyes with neovascular age-related macular degeneration. Am J Ophthalmol 127: 694-709

21. Patel N, Adewoyin T, Chong NV (2008) Age-related macular degeneration: a perspective on genetic studies. Eye (Lond) 22:768-776

22. Janik-Papis K, Zaras M, Krzyzanowska A, Wozniak K, Blasiak J, Szaflik J, Szaflik JP (2009) Association between vascular endothelial growth factor gene polymorphisms and age-related macular degeneration in a Polish population. Exp Mol Pathol 87:234-238

23. Ding X, Patel M, Chan CC (2009) Molecular pathology of agerelated macular degeneration. Prog Retin Eye Res 28(1):1-18

24. Galan A, Ferlin A, Caretti L, Buson G, Sato G, Frigo AC, Foresta C (2010) Association of age-related macular degeneration with polymorphisms in vascular endothelial growth factor and its receptor. Ophthalmology 117:1769-1774

25. Mori K, Horie-Inoue K, Gehlbach PL, Takita H, Kabasawa S, Kawasaki I, Ohkubo T, Kurihara S, Iizuka H, Miyashita Y, Katayama S, Awata T, Yoneya S, Inoue S (2010) Phenotype and genotype characteristics of age-related macular degeneration in a Japanese population. Ophthalmology 117:928-938

26. Kopplin LJ, Igo RP Jr, Wang Y, Sivakumaran TA, Hagstrom SA, Peachey NS, Francis PJ, Klein ML, Sangiovanni JP, Chew EY, Pauer GJ, Sturgill GM, Joshi T, Tian L, Xi Q, Henning AK, Lee KE, Klein R, Klein BE, Iyengar SK (2010) Genome-wide association identifies SKIV2L and MYRIP as protective factors for age-related macular degeneration. Genes Immun 11:609-621

27. Ramensky V, Bork P, Sunyaev S (2002) Human non-synonymous SNPs: server and survey. Nucleic Acids Res 30:3894-3900

28. Centers for Disease Control and Prevention (CDC) (2009) Why is vision loss a public health problem? http://www.cdc.gov/ visionhealth/basic_information/vision_loss.htm. Accessed 20 Oct 2009

29. Green WR (1996) Retina: growth and aging. In: Spenser WH (ed) Ophthalmic pathology, 4th edn. WB Saunders, Philadelphia, pp 676-681

30. Hageman GS, Luthert PJ, Victor Chong NH, Johnson LV, Anderson DH, Mullins RF (2001) An integrated hypothesis that considers drusen as biomarkers of immune-mediated processes at the RPE-Bruch's membrane interface in aging and age-related macular degeneration. Prog Retin Eye Res 20:705-732

31. Bressler NM (2002) Early detection and treatment of neovascular age-related macular degeneration. J Am Board Fam Pract 15:142-152

32. Geirsdottir A, Stefansson E, Jonasson F, Helgadottir G, Sigurdsson $\mathrm{H}$ (2007) Age-related macular degeneration in very old individuals with family history. Am J Ophthalmol 143:889-890

33. Qi S, Wang Y, Zhou M, Ge Y, Yan Y, Wang J, Zhang SS, Zhang S (2011) A mitochondria-localized glutamic acid-rich protein (MGARP/OSAP) is highly expressed in retina that exhibits a large area of intrinsic disorder. Mol Biol Rep 38:2869-2877

34. Totan Y, Yağci R, Bardak Y, Ozyurt H, Kendir F, Yilmaz G, Sahin S, Sahin Tiğ U (2009) Oxidative macromolecular damage in age-related macular degeneration. Curr Eye Res 34:1089-1093 
35. Miyamura N, Ogawa T, Boylan S, Morse LS, Handa JT, Hjelmeland LM (2004) Topographic and age-dependent expression of heme oxygenase- 1 and catalase in the human retinal pigment epithelium. Investig Ophthalmol Vis Sci 45:1562-1565

36. Sun MH, Pang JH, Chen SL, Kuo PC, Chen KJ, Kao LY, Wu JY, Lin KK, Tsao YP (2007) Photoreceptor protection against light damage by AAV-mediated overexpression of heme oxygenase- 1 . Investig Ophthalmol Vis Sci 48:5699-5707

37. Kimura K, Isashiki Y, Sonoda S, Kakiuchi-Matsumoto T, Ohba N (2000) Genetic association of manganese superoxide dismutase with exudative age-related macular degeneration. Am J Ophthalmol 130:769-773

38. Ayala-Haedo JA, Gallins PJ, Whitehead PL, Schwartz SG, Kovach JL, Postel EA, Agarwal A, Wang G, Haines JL, Pericak-Vance MA, Scott WK (2010) Analysis of single nucleotide polymorphisms in the NOS2A gene and interaction with smoking in age-related macular degeneration. Ann Hum Genet 74:195-201

39. Kutty RK, Kutty G, Rodriguez IR, Chader GJ, Wiggert B (1994) Chromosomal localization of the human heme oxygenase genes: heme oxygenase-1 (HMOX1) maps to chromosome 22q12 and heme oxygenase-2 (HMOX2) maps to chromosome 16p13.3. Genomics 20:513-516
40. Abraham NG, Drummond GS, Lutton JD, Kappas A (1996) The biological significance and physiological role of heme oxygenase. Cell Physiol Biochem 6:129-168

41. Hughes AL, Packer B, Welch R, Bergen AW, Chanock SJ, Yeager M (2003) Widespread purifying selection at polymorphic sites in human protein-coding loci. Proc Natl Acad Sci USA 100:15754-15757

42. Ng PC, Henikoff S (2006) Predicting the effects of amino acid substitutions on protein function. Annu Rev Genomics Hum Genet 7:61-80

43. Lee PH, Shatkay H (2008) F-SNP: computationally predicted functional SNPs for disease association studies. Nucleic Acids Res 36:D820-D824

44. Funke C, Tomiuk J, Riess O, Berg D, Soehn AS (2009) Genetic analysis of heme oxygenase-1 (HO-1) in German Parkinson's disease patients. J Neural Transm 116:853-859

45. Shibata N, Ohnuma T, Baba H, Arai H (2009) No genetic association between polymorphisms of heme oxygenase 1 and 2 and Alzheimer's disease in a Japanese population. Dement Geriatr Cogn Disord 27:273-277

46. Maines MD (1997) The heme oxygenase system: a regulator of second messenger gases. Annu Rev Pharmacol Toxicol 37:517-554 